\title{
A new species of Rhabdias Stiles et Hassall, 1905 (Nematoda: Rhabdiasidae) from Blommersia domerguei (Guibé) (Amphibia: Mantellidae) in Madagascar
}

\author{
Yuriy Kuzmin ${ }^{1}$, Kerstin Junker ${ }^{2}$, Louis du Preez ${ }^{3}$ and Odile Bain ${ }^{4+}$ \\ ${ }^{1}$ Department of Parasitology, Institute of Zoology, Kyiv, Ukraine; \\ ${ }^{2}$ ARC-Onderstepoort Veterinary Institute, Onderstepoort, South Africa; \\ ${ }^{3}$ Unit for Environmental Sciences and Management, North-West University, Potchefstroom, South Africa \\ ${ }^{4}$ Muséum National d'Histoire Naturelle, Parasitologie comparée, Paris, France \\ $\dagger$ Deceased: October 16, 2012
}

\begin{abstract}
Rhabdias blommersiae sp. n. (Nematoda: Rhabdiasidae) is described from the lungs of Domergue's Madagascar frog, Blommersia domerguei (Guibé) (Amphibia: Mantellidae), in Madagascar. The new species differs from congeners parasitizing amphibians in having a smaller body and buccal capsule, six equal lips, large excretory glands of unequal length and a posteriorly inflated body vesicle. A combination of characters distinguishes it from Afromalagasy species of Rhabdias Stiles et Hassall, 1905. Rhabdias blommersiae is the third species of the genus described from amphibians in Madagascar. Close similarities in the number and shape of circumoral structures in two Rhabdias species described from mantellid hosts in Madagascar suggest a close relationship and common origin of the two species, with subsequent adaptation to separate hosts within the Mantellidae.
\end{abstract}

Keywords: lung nematodes, Rhabdias blommersiae sp. n., anurans, Blommersia, Afrotropics, morphology

Lung nematodes of the genus Rhabdias Stiles et Hassall, 1905 parasitise amphibian and reptilian hosts worldwide. To date, more than 80 species, of which approximately 50 in amphibians, have been assigned to this genus (Kuzmin and Tkach 2012). A total of eight Rhabdias species have been described from amphibian hosts in the Afrotropics, R. bdellophis Baylis, 1929 from a caecilian and seven species from anurans: R. africanus Kuzmin, 2001; $R$. collaris Baker, 1987; R. madagascariensis Chabaud, Brygoo et Petter, 1961; $R$. ohlerae Junker, Lhermitte-Vallarino et Bain, 2010; $R$. picardiae Junker, Lhermitte-Vallarino et Bain, 2010; R. tanyai Junker, Lhermitte-Vallarino et Bain, 2010 and $R$. vencesi Junker, Lhermitte-Vallarino et Bain, 2010 (see Baylis 1929, Chabaud et al. 1961, Baker 1987, Kuzmin 2001, Junker et al. 2010).

Two of the latter, R. madagascariensis from Ptychadena (syn. Rana) mascareniensis (Duméril et Bibron) (Ptychadenidae) and R. vencesi from Boophis madagascariensis (Peters) (Mantellidae), originate from Madagascar (Chabaud et al. 1961, Junker et al. 2010).

The diversity of Rhabdias species reported from amphibians in the Afrotropical realm is presently lower than that in the Neotropical realm (13 known species) or Palaearctic realm (14 known species). However, recent in- vestigations indicate this to be the result of a lack of data rather than a reflection of the actual status of the genus. In fact, recent data obtained in this region (Cameroonese Volcanic range, South Africa, Madagascar), although still scant, suggest a high diversity of Rhabdias in amphibian as well as reptilian hosts (Lhermitte-Vallarino and Bain 2004, Lhermitte-Vallarino et al. 2008, 2009a,b, 2010a,b, Junker et al. 2010).

In this study, two specimens of Rhabdias recovered from a second mantellid host, the Domergue's Madagascar frog, Blommersia domerguei (Guibé), were examined. Based on their morphology, these specimens were readily assigned to the genus Rhabdias. However, they clearly differed from all presently known species within the genus and are herein described as belonging to a new species, Rhabdias blommersiae. Their morphological characters and affinities to their Afrotropical congeners from amphibian hosts are discussed.

\section{MATERIALS AND METHODS}

The two specimens described below were part of a collection of helminths from amphibians of one of the authors (LdP; PL050118H1 and PL050118H2) and had been collected from Blommersia domerguei (LdP; AL050118A3) during an un- 
related study in Madagascar. They are now deposited in the collection of zooparasitic nematodes of the Muséum National d'Histoire Naturelle, Paris, France (MNHN), accession number $352 \mathrm{YU}$, as holotype and paratype, respectively. The specimens had been fixed and stored in $70 \%$ ethanol. For morphological studies, they were cleared in lactophenol and examined under a Wild compound microscope equipped with a drawing tube.

Measurements were taken from drawings and are given in micrometres unless otherwise specified. Cephalic and buccal structures (velum, vestibule, buccal cavity, buccal capsule) were identified and measured as described in Lhermitte-Vallarino et al. (2010a). In accordance with earlier publications, four ratios are provided (Tkach et al. 2006, Martínez-Salazar and LeónRègagnon 2007, Lhermitte-Vallarino et al. 2008). The genital tract was studied in detail to identify spermatozoa and the testis zone (Runey et al. 1978), since these biological characters may be of interest to our understanding of the evolution of Rhabdias. A holotype specimen of the closely related species $R$. madagascariensis (MNHN E188) was used for comparative studies. In this specimen the head is absent. Nomenclature of amphibian hosts follows Frost (2013).

\section{RESULTS}

\section{Rhabdias blommersiae sp. $\mathrm{n}$.}

Figs. 1-8

Description (based on two gravid individuals; measurements are given for the holotype, followed by the paratype in parentheses). Relatively small species. Body length 3.6 (3.2) mm, maximum width at mid-body 185 (180). Body tapering towards both extremities; anterior end rounded, posterior end attenuated (Fig. 6). Body cuticle slightly inflated in anterior part, thin at mid-body, distinctly inflated in posterior part, with deep irregular transverse folds (Fig. 8).

Oral opening small, round (Fig. 2). Six circumoral lips, approximately equal in shape and size, each bearing a small papilla. Amphids indistinct. All lips distant from mouth, but lateral ones at somewhat larger distance (Fig. 2). Vestibulum 6 (6) deep. Velum absent. Buccal capsule 7 (8) long and 11 (12) wide, round in apical view (Fig. 3), wide barrel-shaped in lateral view, with thick walls and cylindrical lumen (Fig. 1); buccal capsule ratio $0.6(0.7)$. Oesophagus club-shaped, without shoulders and without dilation in muscular part (Fig. 4), 330 (310) long, reaching $9.2(9.6) \%$ of body length. Width of oesophagus 32 (29) at anterior end, 37 (37) at mid-length. Posterior bulb oval-shaped, 66 (74) wide. Nerve ring at 115 (122) from anterior end of oesophagus, slightly anterior to its mid-length.

Excretory pore posterior to level of nerve ring, at 180 (160) from anterior end. Excretory channel short and straight, 22 (25) long. Excretory glands (Fig. 4) prominent, differing in length: one 210 (180) long, ending just posterior to oesophageal-intestinal junction; the other 370 (330) long, extending far beyond oesophageal-intestinal junction. Intestine thick-walled; in holotype, apex of intestine narrow, but widening abruptly posterior to oesophageal-intestinal junction (Fig. 4); in paratype, apex of intestine broad with shallow depression that accommodates narrower oesophageal bulb (Fig. 6). Rectum cylindrical, slightly twisted, with weakly cuticularized walls (Fig. 5).

Vulva pre-equatorial, slightly salient (Fig. 7), situated at $1.57(1.52) \mathrm{mm}$ from anterior end, i.e. $43(47) \%$ of body length. Vagina transverse, short, straight, cuticularized (Fig. 7). Uteri amphidelphic, approximately equal, thin-walled, tubular, with eggs arranged in 2-3 longitudinal rows; most eggs near vulva containing first-stage larvae. Egg size 80-105 × 50-60 (five eggs each from holotype and paratype, measured in uteri). Anterior branch of uterus almost reaching level of oesophageal-intestinal junction (Fig. 6), posterior genital bend at 650 (630) from posterior end (Fig. 8); both anterior and posterior genital bend at distal part of ovaries. Proximal ends of ovaries slightly overlapping at level of vulva (Fig. 7). Testis zone and spermatozoa could not be identified in ovaries. Oviducts short and straight.

Tail short, conical, 147 (142) long, i.e. 4.1\% (4.4)\% of body length. Caudal vesicle inflated, completely enclosing tip of tail, invaginated on tail tip (Fig. 5) in both specimens.

Type host: Domergue's Madagascar frog, Blommersia domerguei (Guibé) (Amphibia: Mantellidae); host (field No. AL05011813) collected on 18 January 2005.

Type locality: Madagascar, Special Reserve Ambohitantely, $125 \mathrm{~km}$ north of Antananarivo (18 $\left.08^{\circ} 59^{\prime \prime} \mathrm{S} ; 4^{\circ} 17^{\prime} 00^{\prime \prime} \mathrm{E}\right)$. Altitude 1448-1 $662 \mathrm{~m}$ (Stephenson et al. 1994).

Site in host: Lungs.

Prevalence and intensity of infection: One of five examined host specimens harboured two R. blommersiae specimens.

Type material: Holotype and one paratype deposited in the MNHN collection (accession number $352 \mathrm{YU}$ ).

E ty mology: This species is named after its type host genus.

Remarks. In size, oesophagus and tail length, distance from the apex to the vulva and egg size, $R$. blommersiae sp. n. resembles its sympatric congener $R$. madagascariensis, particularly the holotype described by Chabaud et al. (1961). However, the anterior end of $R$. madagascariensis is truncated and the circumoral lips and buccal capsule are indistinct, its oesophagus possesses a prominent dilation just anterior to the nerve ring, and the excretory glands are similar in length, $400 \mu \mathrm{m}$ and $350 \mu \mathrm{m}$, respectively (Chabaud et al. 1961). In addition, a prominent excretory sinus is absent in $R$. madagascariensis, the intestine is narrower than the oesophageal bulb, and the body vesicle is inconspicuous in the posterior part of the body and does not reach the tip of the tail (Chabaud et al. 1961; own observations).

The shape of the anterior end, oesophagus and body vesicle, as well as the presence of six small lips, approach $R$. blommersiae to the second species from Malagasy am- 

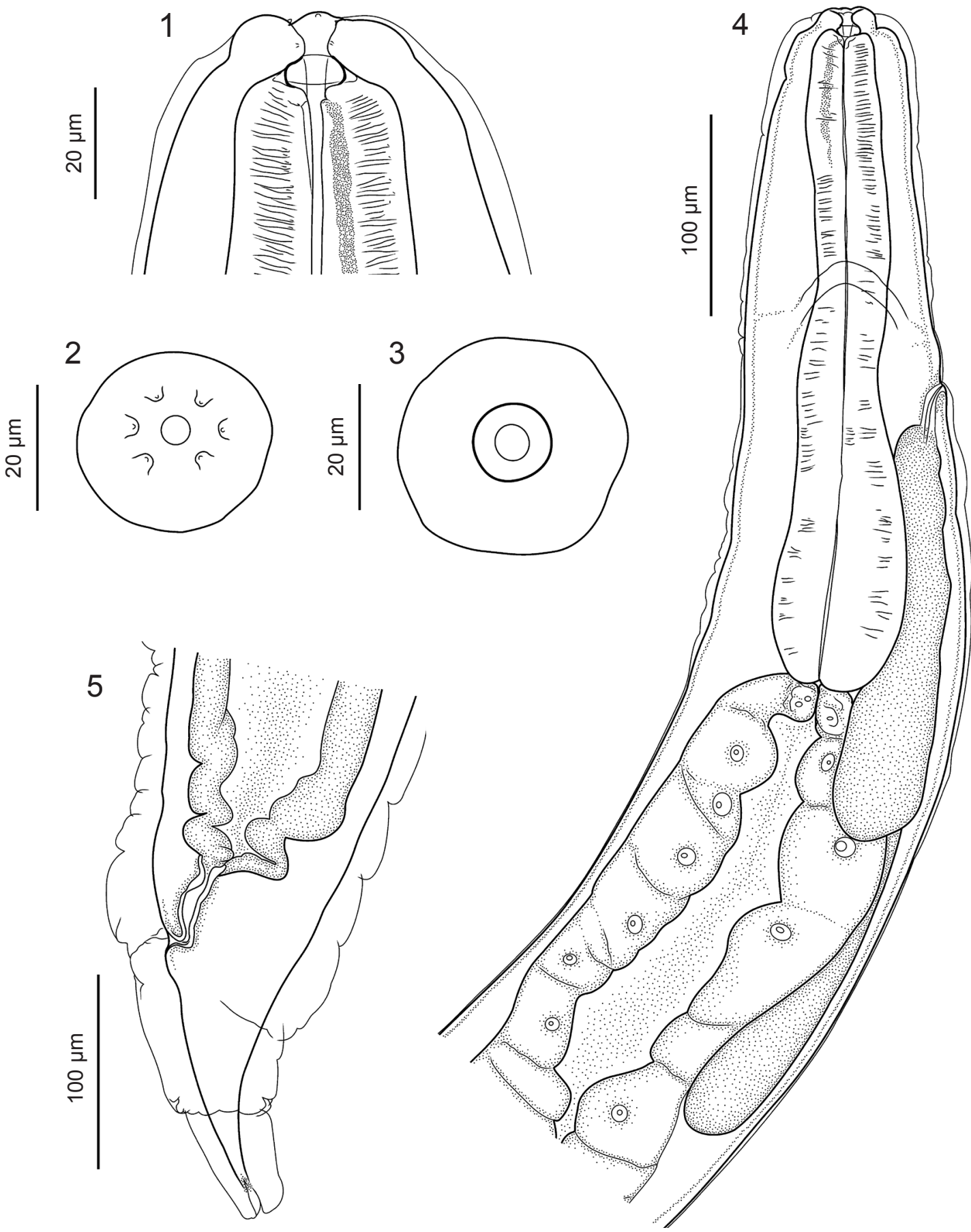

Figs. 1-5. Rhabdias blommersiae sp. n. from Blommersia domerguei (Guibé) in Madagascar. Fig. 1. Anterior end, lateral view (holotype). Fig. 2. Anterior end, apical view (paratype). Fig. 3. Anterior end, apical view, optical section at level of buccal capsule at mid-depth (paratype). Fig. 4. Anterior part, lateral view (holotype). Fig. 5. Posterior end, lateral view (holotype).

phibians, $R$. vencesi. The latter is, however, much larger (9.5-13.2 mm long), its buccal capsule is about twice as wide as that of $R$. blommersiae (19-22 $\mu \mathrm{m} v s$ 11-12 $\mu \mathrm{m})$; an anterior dilation is present in the oesophagus and the posterior part of the tail is enclosed in a thin, non-inflated vesicle (Junker et al. 2010).

A further six Rhabdias species have been described from amphibians on the African continent. Rhabdias bdellophis from the caeciliid Scolecomorphus vittatus (Boulenger) (syn. Bdellophis vittatus), and the remaining five from anurans. The former differs from $R$. blommersiae in being slightly larger (5.1-5.6 mm vs 3.2-3.6 mm) and having a smaller oesophagus and tail ratio (7.8-8.0 and 2.5-2.8\% vs 9.2-9.6 and 4.1-4.4\%, respectively). Its buccal capsule is described as 'vague' (Baylis 1929), as opposed to a small but distinct buccal capsule in $R$. blommersiae. 

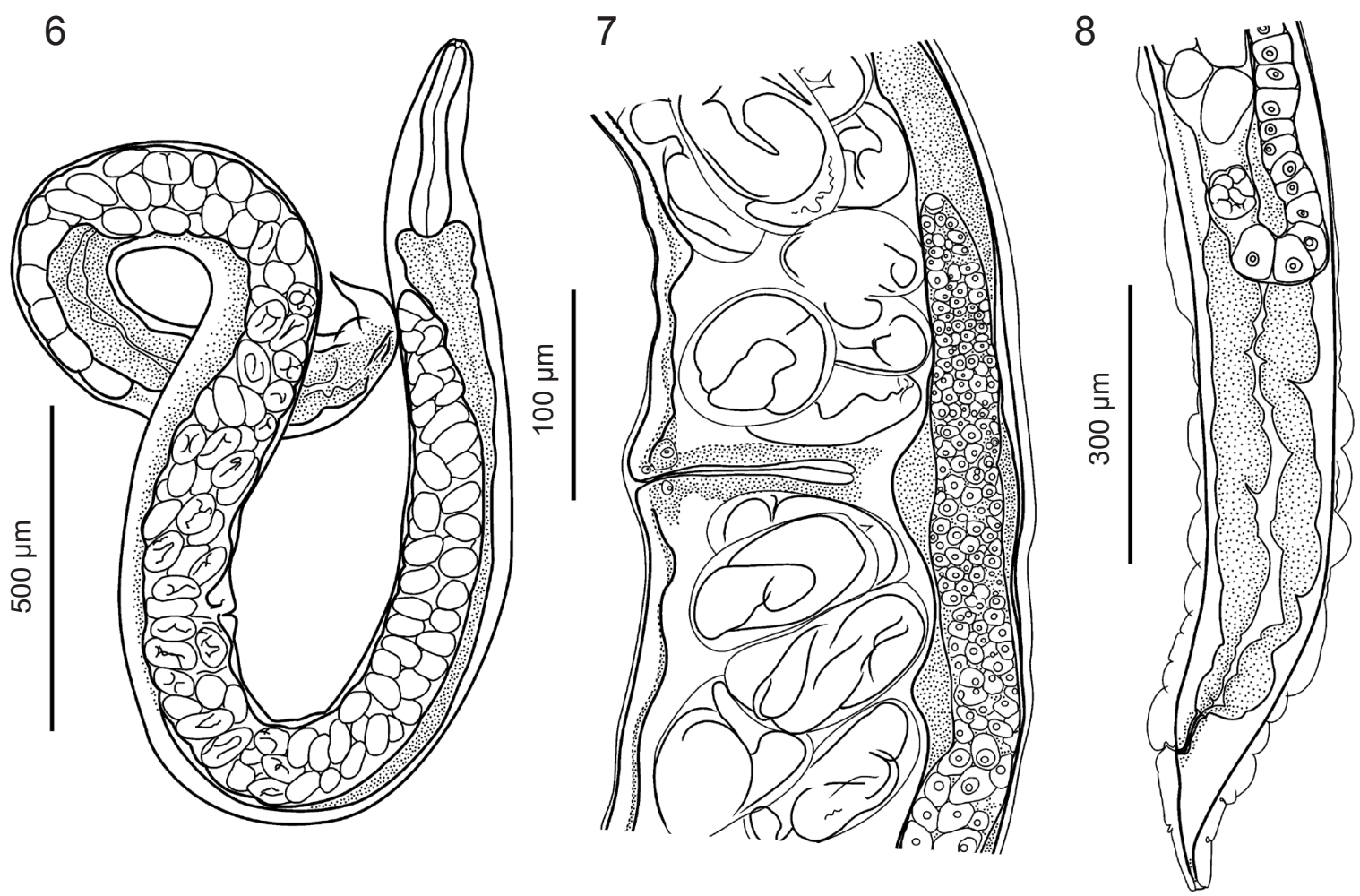

Figs. 6-8. Rhabdias blommersiae sp. n. from Blommersia domerguei (Guibé) in Madagascar. Fig. 6. General view showing the extent of the genital tract (paratype); body vesicle not shown. Fig. 7. Vulva region, lateral view (paratype). Fig. 8. Posterior end, lateral view (holotype).

The longer body and a conspicuous cephalic dilation readily distinguish $R$. collaris from Leptopelis vermiculatus (Boulenger) (Arthroleptidae) in Tanzania from the new species. This also holds true for $R$. ohlerae from L. brevirostris (Werner) (Arthroleptidae) in Cameroon (see Baker 1987, Junker et al. 2010). The remaining four species are also larger in size. In addition, in $R$. tanyai from Astylosternus rheophilus Amiet (Arthroleptidae) in Cameroon, a short, flat-topped anterior projection encloses the buccal capsule and the oesophagus ratio reaches a maximum of $4.7 \%$ (Junker et al. 2010).

The following two species are parasitic in Bufonidae in South Africa: R. africanus from Amietophrynus maculatus (Hallowell) differs from $R$. blommersiae in having a wider buccal capsule $(20-23 \mu \mathrm{m})$ and a shorter oesophagus ratio $(3.5-4.7 \%$ vs $9.2-9.6 \%)$ (Kuzmin 2001); R. picardiae from A. gutturalis (Power) can be distinguished by its wider buccal capsule $(23-25 \mu \mathrm{m})$, elongated oesophagus and its post-equatorial vulva (Junker et al. 2010).

We thus conclude that the specimens from $B$. domerguei in Madagascar represent a new species for which we propose the name $R$. blommersiae.

\section{DISCUSSION}

The amphibian fauna of Madagascar is considered one of the world's most important 'hot spots' for amphib- ian diversity, with more than 240 species described, the majority of which are endemic and many of which are characterized by small geographic ranges (Andreone et al. 2008, 2010, Vences et al. 2010). Its long isolation from other land masses, together with its large size and varied topography, are considered some of the main contributing factors to its faunal diversity (Fisher 1996). Despite this astounding host diversity, only three Rhabdias species from Malagasy amphibians have been studied to date.

Two of these, $R$. vencesi and $R$. blommersiae, have been described from mantellid hosts that are endemic to Madagascar. Blommersia domerguei occurs on the plateau of central Madagascar and its eastern slopes, where it has been recorded from 900 to $2000 \mathrm{~m}$ above sea level. Its geographic range partially overlaps with that of Boophis madagascariensis, which is found from sea level up to altitudes of $1700 \mathrm{~m}$ and inhabits numerous localities in eastern and central Madagascar. Of the three amphibian hosts of Rhabdias in Madagascar, Ptychadena mascareniensis has the widest geographic distribution, being found throughout Madagascar, at altitudes ranging from sea level to over $2000 \mathrm{~m}$ (Nussbaum and Vallan 2004, Vallan and Glaw 2004, Rödel et al. 2009); it also has a wide distribution in sub-Saharan Africa and molecular evidence suggests that it reached Madagascar through transoceanic dispersal long before human settlement (Vences et al. 2004, Frost 2013). 
Because of the relative geographic isolation of Malagasy hosts and, consequently, their parasites, one might expect to find characters that unite the three Rhabdias species from Malagasy amphibians and oppose them to other congeners. Whereas specimens from Madagascar share a stout, distinctly club-shaped oesophagus, this is not a characteristic restricted to them, but is present in numerous other Rhabdias species from amphibians, including newts and salamanders, worldwide (Baker 1987, Goodey 1924, Kuzmin et al. 2001, 2003, Kuzmin 2005, MartínezSalazar 2008). Oesophagus shape in general does not seem to relate to either geographic origin or host phylogeny.

A further character shared by all three Rhabdias species from Malagasy amphibians are conspicuous excretory glands, but they have also been observed in Rhabdias species from amphibians from other geographic regions, e.g. R. alabialis Kuzmin, Tkach et Brooks, 2007 from Costa Rica, R. bicornis Lu, 1934 and R. globocephala Kung et Wu, 1945 from China (Lu 1934, Kuzmin 2005, Kuzmin et al. 2007).

Similarly, small-sized species of Rhabdias (body length of gravid individuals $<5 \mathrm{~mm}$ ) do not seem to form a separate group of related species within the genus Rhabdias in amphibian hosts either. Rhabdias blommersiae differs from species that are of similar size, $R$. australiensis Moravec et Sey, 1990, R. joaquinensis Ingles, 1936 and $R$. savagei Bursey et Goldberg, 2005, in a number of characters including the morphology of the anterior end. Rhabdias blommersiae possesses six small lips that are similar in shape and size. Four lips were ob- served in $R$. savagei and $R$. joaquinensis, the latter species also possessing two rounded pseudolabia (Kuzmin et al. 2003, Bursey and Goldberg 2005). Based on the shape and position of circumoral structures, the latter two species may be assumed to be more closely related, which is also supported by their specificity to hosts of the genus Rana Linnaeus, as well as their geographic distribution in the Americas. No lips or papillae were reported in the description of $R$. australiensis (one specimen available; Moravec and Sey 1990).

The number, shape and position of circumoral structures are equally similar in two of the species from Madagascar, $R$. vencesi and $R$. blommersiae. Their specificity to frogs of the family Mantellidae, as additional character, may indicate a close relationship and common origin. In this case, speciation within Rhabdias might have occurred as a result of adaptation to separate hosts within the Mantellidae. Given that the diversity of potential amphibian hosts in Madagascar is very high, it is likely that the diversity of Rhabdias species parasitizing Malagasy amphibians is distinctly higher than currently reflected in the literature.

Acknowledgments. Y. Kuzmin and K. Junker were sponsored during a two-month's visit as invited professors by the Muséum National d'Histoire Naturelle, Paris, France.

Note: Yuriy Kuzmin, Kerstin Junker and Louis du Preez would like to acknowledge their cherished colleague Dr. Odile Bain, who passed away on October 16, 2012. During her life's work she made a vast contribution to nematode biology and systematics; her enthusiasm and expertise will be sorely missed.

\section{REFERENCES}

Andreone F., Carpenter A.I., Cox N., du Preez L., Freeman K., Furrer S., Garcia G., Glaw F., Glos J., Knox D., KöhLer J., Mendelson J.R. III, Mercurio V., Mittermeier R.A., Moore R.D., Rabibisoa N.H.C., Randriamahazo H., RanDrianasolo H., Rasoamampionona Raminosoa N., Ravoahangimalala Ramilijaona O., Raxworthy C.J., Vallan D., Vences M., Vieites D.R., Weldon C. 2008: The challenge of conserving amphibian megadiversity in Madagascar. PLoS Biol. 6: 943-946.

Andreone F., Rosa G.M., Noël J., Crottini A., Vences M., RAXworthy C.J. 2010: Living within fallen palm leaves: the discovery of an unknown Blommersia (Mantellidae: Anura) reveals a new reproductive strategy in the amphibians of Madagascar. Naturwissenschaften 97: 525-543.

BAKER M.R. 1987: Rhabdias collaris n. sp. (Nematoda: Rhabdiasidae) from frogs of Tanzania. Syst. Parasitol. 9: 199-201.

BAylis H.A. 1929: Some parasitic nematodes from the Uluguru and Usambara Mountains, Tanganyika Territory. Ann. Mag. Nat. Hist. 10: 372-381.

Bursey C.R., Goldberg S.R. 2005: New species of Oswaldocruzia (Nematoda: Molineoidae), new species of Rhabdias (Nematoda: Rhabdiasidae), and other helminths in Rana cf. forreri (Anura: Ranidae) from Costa Rica. J. Parasitol. 91: 600-605.
Chabaud A.G., Brygoo E.R., Petter A.J. 1961: Description et caractères biologiques de deux noveaux Rhabdias malgaches. Ann. Parasitol. Hum. Comp. 36: 752-763.

Fisher B.L. 1996: Origins and affinities of the ant fauna of Madagascar. In: W.L. Lourenço (Ed.), Biogéographie de Madagascar. Editions Orstom, Paris, pp. 457-465.

Frost D.R. (Ed.) 2013: Amphibian Species of the World: an online reference (version 5.6.), American Museum of Natural History, New York, http://research.amnh.org/vz/herpetology/ amphibia, 4/2013.

Goodey T. 1924: Two new species of the nematode genus Rhabdias. J. Helminthol. 2: 203-208.

IUCN 2011. IUCN Red List of Threatened Species (version 2012.2), www.iucnredlist.org, 4/2013.

Junker K., Lhermitte-Vallarino N., Barbuto M., Ineich I., WANJi S., BAIn O. 2010: New species of Rhabdias (Nematoda: Rhabdiasidae) from Afrotropical anurans, including molecular evidence and notes on biology. Fol. Parasitol. 57: 47-61.

Kuzmin Y.I. 2001: Rhabdias africanus sp. n. (Nematoda, Rhabdiasidae), a new nematode species from South African toads (Amphibia, Bufonidae). Acta Parasitol. 46: 148-150.

Kuzmin Y.I. 2005: The description of Rhabdias globocephala (Nematoda, Rhabdiasidae) from the new host Buergeria pollicaris (Amphibia, Rhacophoridae). Vest. Zool. 39: 9-14. 
KuZmin Y., TKach V.V. 2012. Rhabdias, www.izan.kiev.ua/ppages/rhabdias, 4/2013.

Kuzmin Y., Tкасн V.V., Brooks D.R. 2007: Two new species of Rhabdias (Nematoda: Rhabdiasidae) from the marine toad, Bufo marinus (L.) (Lissamphibia: Anura: Bufonidae), in Central America. J. Parasitol. 93: 159-165.

Kuzmin Y., TKach V.V., Snyder S.D. 2001: Rhabdias ambystomae sp. n. (Nematoda: Rhabdiasidae) from the North American spotted salamander Ambystoma maculatum (Amphibia: Ambystomatidae). Comp. Parasitol. 68: 228-235.

Kuzmin Y., Tkach V.V., Snyder S.D. 2003: The nematode genus Rhabdias (Nematoda: Rhabdiasidae) from amphibians and reptiles of the Nearctic. Comp. Parasitol. 70: 101-114.

Lhermitte-Vallarino N., Bain O. 2004: Morphological and biological study of Rhabdias spp. (Nematoda) from African chameleons with description of a new species. Parasite 11: 15-31.

Lhermitte-Vallarino N., Barbuto M., Ineich I., Wanji S., LeBREton M., Chirio L., BAin O. 2008: First report of Rhabdias (Nematoda: Rhabdiasoidea) from lungs of montane chameleons in Cameroon: description of two new species and notes on biology. Parasite 15: 553-564.

Lhermitte-Vallarino N., Barbuto M., Junker K., Boistel R., BAIN O. 2010a: Rhabdias (Nematoda: Rhabdiasidae) from Chamaeleonidae (Sauria): two new species from Trioceros ellioti in East Africa and one from Brookesia superciliaris in Madagascar. Parasite 17: 91-105.

Lhermitte-Vallarino N., Barbuto M., Junker K., Boistel R., InEICH I., WANJI S., BAIN O. 2009a: Rhabdias rhampholeonis n. sp. and $R$. mariauxi n. sp. (Nematoda, Rhabdiasoidea), first lung worms from leaf chameleons: description, molecular evidence and notes on biology. Parasitol. Int. 58: 375-383.

Lhermitte-Vallarino N., Barbuto M., Junker K., Wanji S., Ineich I., Schmitz A., Bain O. 2010b: The lung nematode parasites of the genus Rhabdias (Rhabdiasidae): diversity and biology in the Chamaeleonidae (Squamata) and hypotheses on their evolution. Bull. Soc. Zool. France 135: 107-116.

Lhermitte-Vallarino N., Junker K., Bain O. 2009b: Reappraisal of the specific status of Rhabdias (Nematoda) from Malagasy chameleons in the Paris Museum collection. Parasite 16: $111-123$

Lu S.C. 1934: On Rhabdias, a genus of parasitic Nematoda, of Nanking. Sinensia 5: 164-172.
Martínez-Salazar E.A. 2008: A new rhabdiasid species from Craugastor occidentalis (Anura: Brachycephalidae) from Sierra Manantlán, Jalisco, Mexico. Rev. Mex. Biodiv. 79: 81-89.

Martínez-Salazar E.A., LeÓn-RĖGagnon V. 2007: New species of Rhabdias (Nematoda: Rhabdiasidae) from Bufo occidentalis (Anura: Bufonidae) from Sierra Madre del Sur, Mexico. J. Parasitol. 93: 1171-1177.

Moravec F., Sey O. 1990. Some nematode parasites of frogs from Papua New Guinea and Australia. Acta Soc. Zool. Bohem. 54: 268-286.

Nussbaum R., Valland D. 2004: Boophis madagascariensis. In: International Union for Conservation of Nature 2012. IUCN Red List of Threatened Species (version 2012.2.), www.iucnredlist.org, 06/2013.

Röbel M.-O., Largen M., Minter L., Howell K., Nussbaum R., Vences M., Baha El Din S. 2009: Ptychadena mascareniensis. In: International Union for Conservation of Nature 2012. IUCN Red List of Threatened Species (version 2012.2.), www.iucnredlist.org, 06/2013.

Runey W.M., Runey G.L., Lauter F.H. 1978: Gametogenesis and fertilization in Rhabdias ranae Walton 1929: I. The parasitic hermaphrodite. J. Parasitol. 64: 1008-1014.

Stephenson P.J., Randriamahazo H., Rakotoarison N., Racey P.A. 1994: Conservation of mammalian species diversity in Ambohitantely Special Reserve, Madagascar. Biol. Cons. 69: 213-218.

Tкасн V.V., Kuzmin Y., Pulis E.E. 2006: A new species of Rhabdias from lungs of the wood frog, Rana sylvatica, in North America: the last sibling of Rhabdias ranae? J. Parasitol. 92: 631-636.

Vallan D., Glaw F. 2004: Blommersia domerguei. In: International Union for Conservation of Nature 2012. IUCN Red List of Threatened Species (version 2012.2.), www.iucnredlist.org, $06 / 2013$

Vences M., Köhler J., Pabijan M., Glaw F. 2010: Two synoptic and microendemic new frogs of the genus Blommersia from the east coast of Madagascar. Afr. J. Herpetol. 59, 133-156.

Vences M., Kosuch J., Rödel M-O., Lötters S., Channing A., Glaw F., BöHme W. 2004: Phylogeography of Ptychadena mascareniensis suggests transoceanic dispersal in a widespread African-Malagasy frog lineage. J. Biogeogr. 31: 593-601. 